\title{
Author Correction: Efficient green light-emitting diodes based on quasi-two-dimensional composition and phase engineered perovskite with surface passivation
}

Xiaolei Yang ${ }^{1,2}$, Xingwang Zhang 1,3, Jinxiang Deng ${ }^{2}$, Zema Chu ${ }^{1}$ Qi Jiang ${ }^{1,3}$, Junhua Meng ${ }^{1,3}$, Pengyang Wang ${ }^{1,3}$, Liuqi Zhang ${ }^{1,3}$, Zhigang Yin ${ }^{1,3} \&$ Jingbi You (1) ${ }^{1,3}$

Correction to: Nature Communications (2017) https://doi.org/10.1038/s41467-018-02978-7; Article published online: 08 Feb 2018

The original version of this Article omitted an acknowledgement to the source of Fig. 1a. The following has been added to the end of the caption to Fig. 1:

'Figure 1a adapted from ref. 13 (copyright 2016 Macmillan Publishers)'.

This has been corrected in the PDF and HTML versions of the Article.

Published online: 16 March 2018

\begin{abstract}
(c) Open Access This article is licensed under a Creative Commons Attribution 4.0 International License, which permits use, sharing, adaptation, distribution and reproduction in any medium or format, as long as you give appropriate credit to the original author(s) and the source, provide a link to the Creative Commons license, and indicate if changes were made. The images or other third party material in this article are included in the article's Creative Commons license, unless indicated otherwise in a credit line to the material. If material is not included in the article's Creative Commons license and your intended use is not permitted by statutory regulation or exceeds the permitted use, you will need to obtain permission directly from the copyright holder. To view a copy of this license, visit http://creativecommons.org/licenses/by/4.0/.
\end{abstract}

(๑) The Author(s) 2018

\footnotetext{
${ }^{1}$ Key Laboratory of Semiconductor Materials Science, Institute of Semiconductors, Chinese Academy of Sciences, 100083 Beijing, China. ${ }^{2}$ College of Applied Sciences, Beijing University of Technology, 100124 Beijing, China. ${ }^{3}$ College of Materials Science and Opto-electronic Technology, University of Chinese Academy of Sciences, 100049 Beijing, China. Correspondence and requests for materials should be addressed to J.Y. (email: jyou@semi.ac.cn)
} 